\title{
Research on the Effect of 4C $+2 S$ to Customer Perceived Value in Scene Marketing of Clothing Industry in China
}

\author{
Yuan Wang \\ School of Management, Jinan University, Guangzhou, China \\ Email: ecwangyuan@126.com
}

How to cite this paper: Wang, Y. (2020) Research on the Effect of $4 \mathrm{C}+2 \mathrm{~S}$ to Customer Perceived Value in Scene Marketing of Clothing Industry in China. Open Journal of Business and Management, $\mathbf{8}$, 628-638.

https://doi.org/10.4236/ojbm.2020.82037

Received: February 15, 2020

Accepted: March 2, 2020

Published: March 5, 2020

Copyright $\odot 2020$ by author(s) and Scientific Research Publishing Inc. This work is licensed under the Creative Commons Attribution International License (CC BY 4.0). http://creativecommons.org/licenses/by/4.0/

\begin{abstract}
The article has made a research on the effect of $4 \mathrm{C}+2 \mathrm{~S}$ to customer perceived value in scene marketing of clothing industry in China, according to customer perceived value and 4C marketing theory. First of all, tease out the four dimensions of customer perceived value through the literatures. Then build the conceptual model, put forward relevant hypotheses and with "offline experience, online order" mode as the research object, design scale to verify the hypothesis. Then, analyze data by SPSS19 and AMOS 22. The research results show that customer value, communication and streaming data have significant influence on customer perceived value. The second is convenient. Finally, put forward the suggestions to improve the effect of scene marketing for online clothing brands.
\end{abstract}

\section{Keywords \\ 4C, Clothing, Scene Marketing, CPV}

\section{Introduction}

In recent years, China's scene marketing development has become increasingly rapid. Speaking of scene marketing, we must start with "new retail". On October 13, 2016, Jack Ma first mentioned the word "new retail" at the Alicloud Conference in Hangzhou. He pointed out that there will be no e-commerce in the future, only new retail, which means that online and offline must be combined. This theory is generally accepted in the industry. And this has just promoted the development of scene marketing. Due to the limited space, this article will focus on the most widely used scene marketing in the clothing industry. As a marketing method, the result of scene marketing is determined by customers. There- 
fore, only through scene marketing can make customers feel excellent perceived value, so that the company can stand out from competitors. So, customer perceived value $(\mathrm{CPV})$ is becoming increasingly important.

There are many views on the definition of CPV, such as the rational trade-off view, the single-dimensional and multi-dimensional view, and the process-result view. At present, the most easily accepted and most popular application is the concept of rational trade-off, that is, under the condition of customer rationality, the purchase decision is made by comparing benefits and costs.

For the application of CPV theory in e-commerce, Jarvenpaa summarized the factors that influence consumers' shopping on e-commerce platforms, which are products, services, experiences and risks. Marghero believed that convenience is important in the process of consumers choosing to consume on e-commerce platforms. Mathwick et al. developed the Experience Value Scale (EVS) to analyze the perceived value of consumers shopping in an e-commerce environment. Yung-Hsiang Cheng and Wei-Chih Tseng [1] explored the tourism and development of subway passengers using intermodal transfer services and buses in the subway system based on the research hypothesis of perceived value theory. Heetae Yang [2] analyzed the perceived value of customers using wearable devices.

In short, although there are many studies on the application of CPV in e-commerce and the entry points are relatively detailed, the pertinence is generally not strong. At present, it is not possible to provide very systematic guidance for the practice of e-commerce. Therefore, this article takes the customer as the center, puts the customer in the entire clothing scene marketing environment, and combines the $4 \mathrm{C}$ theoretical factors, namely customer value, cost, convenience, and communication. The two important factors of surroundings and streaming data are creatively combined into six factors of " $4 \mathrm{C}+2 \mathrm{~S}$ ". Through empirical research, we deeply explore the impact of each factor on CPV in order to give references for the transformation of traditional e-commerce enterprises.

\section{The Establishment of the Hypothetical Model}

Regarding the constituent dimensions of $\mathrm{CPV}$, there is no unified conclusion. Deng Feng [3] summarized the previous measurement of the CPV dimension, and proposed that CPV mainly has dimensions such as price, quality, society, service, and emotional value, and pointed out that the main difference between traditional shopping and online shopping is the change of service value. Through empirical analysis, Lu Yaxin [4] concluded that in the clothing retail, products, services, and the environment have a positive effect on CPV, also emphasized the impact of clothing store image on CPV, focusing on the two dimensions of quality value and service value. Huang Jie [5] found that service and emotion have a greater impact on the CPV of female college students' clothing market. In summary, the dimensions of function, service, social and emotion value are widely recognized. Based on the above discussion, this article will use these four dimensions to analyze CPV. 
$4 \mathrm{C}$ is actually developed by $4 \mathrm{P}$. The nature of $4 \mathrm{P}$ theory is enterprise-centered, and it mainly considers what the enterprise wants to produce or provide, what price to set, how to spread and promote, and what channels to choose for sales. However, with the development of the market, the center of the market has gradually changed from enterprises to customers. For this reason, Professor Lauterborn proposed the 4C marketing theory in 1990. Among them, 4C refers to Customer Value, Cost, Convenience, and Communication. Until now, these two theories are still not outdated, and they continue to develop under different marketing scenes. It emphasizes that companies should first pursue the pursuit of customer satisfaction, secondly, strive to reduce customer purchase costs, and then pay full attention to the convenience of customers in the purchase process, rather than determine the sales channel strategy from the perspective of the company, and finally consumer-focused marketing communications should be effective [6].

For 4C, 1) Customers mainly refer customer value. Enterprises must first understand and research customers, and provide products according to customer needs. At the same time, the company provides not only products and services, but also the resulting customer value [7]; 2) Cost is not only the production cost of the enterprise, it also includes the purchase cost of the customer, and it also means the product The ideal situation of pricing should be lower than the psychological price of customers, and it can make the company profitable. In addition, the intermediate customer's purchase cost includes not only its currency expenditure, but also the time, physical and energy expenditure, and purchase risk it consumes. When buying goods, customers always want to minimize the relevant costs, including currency, time, spirit and physical strength, so as to maximize their satisfaction [8]; 3) Convenience is to provide customers with the greatest convenience in shopping and use. $4 \mathrm{C}$ marketing theory emphasizes that when formulating a distribution strategy, companies should consider the convenience of customers more than the convenience of the company itself. Through good pre-sale, sale and after-sales service, customers can enjoy convenience while shopping. Convenience is an integral part of customer value [9]; 4) Communication includes providing consumers with information about store locations, goods, services, prices, etc.; affecting consumers' attitudes and preferences, persuading consumers to patronize stores and buying goods; Establish a good corporate image in the minds of consumers [10].

$2 \mathrm{~S}$, namely surroundings and streaming data, are summarized by the author based on previous research and her own practice. Baker's research [11] shows that the shopping environment can affect customer satisfaction. Jin Yufang [12] pointed out that the store environment can positively affect customer trust. Wang Xuhui [13] proposed that enterprises optimize and innovate the store environment, which can attract consumers to buy. Yu Lin [14] put forward and verified the importance of the environment to the development of enterprises It can be seen that the influence of the environment on consumer trust and per- 
ceived value is very obvious, especially in the offline marketing environment, which coincides with the scene marketing discussed in this article; As for streaming data, not to mention the role of the scene marketing. The data here includes both the company's timely grasp of the customer's data and the customer's grasp of all aspects of the company's latest data. As mentioned earlier, most scholars have emphasized the precise push and emotional connection of scene marketing, and precise push relies on mobile data.

In summary, the impact of $4 \mathrm{C}$ and $2 \mathrm{~S}$ on $\mathrm{CPV}$ in scene marketing is indispensable. However, as to how they affect, there is little description in the previous literature. Therefore, this article will choose the most representative "offline experience, online order" form in the clothing industry as the research object, and study the influence of six factors on CPV in the scene marketing of clothing industry, and put forward the following hypotheses, as shown in Table 1. And based on the 24 hypotheses, a hypothetical model of the six factors' impact on CPV in scene marketing in the clothing industry can be constructed, as shown in Figure 1.

Table 1. Hypothesis establishment.

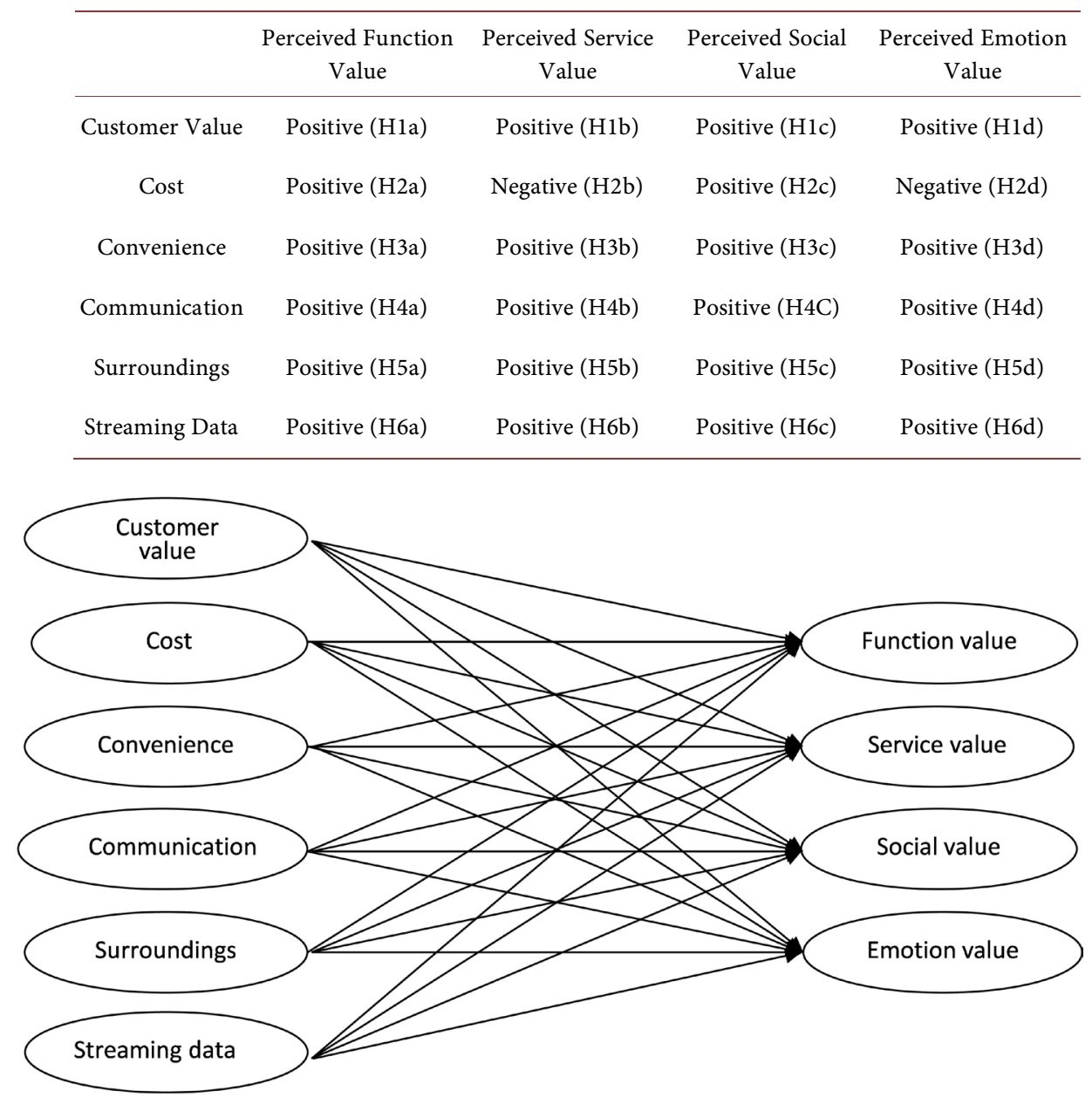

Figure 1. Hypothetical model. 


\section{Questionnaire Design and Analysis}

\subsection{Survey Design}

The purpose of this article is to study the impact of $4 \mathrm{C}+2 \mathrm{~S}$ on the CPV of clothing scene marketing. In order to make the research more meticulous and more targeted, the article has selected the most representative "offline experience, online order" model in the clothing scene marketing. Based on the hypothetical model of $4 \mathrm{C}+2 \mathrm{~S}$ 's impact on $\mathrm{CPV}$ in the scene marketing of the clothing industry, a questionnaire was designed to obtain primary data to verify the hypothetical model. In addition to the respondents' basic information such as gender, age, monthly income, the questionnaire includes the following 10 survey items: customer value, cost, convenience, communication, environment, streaming data, perceived function value, perceived service value, perceived social value, and perception emotion value. Considering the use of AMOS 22 for empirical analysis, most of the questions in the questionnaire have been designed with Likert scales. Considering accuracy and ease of operation, the questionnaires have adopted Level 5 Likert scales. The design of the CPV scale refers to the study of Sweeney et al. (2007), with a total of 16 measurement items, as shown in Table 2.

\subsection{Reliability and Validity Analysis}

In order to ensure the rationality of the questionnaire, it is necessary to analyze the reliability and validity of the questionnaire before fitting the model. First calculate the $\alpha$ coefficient of each measurement variable to verify its internal consistency. The $\alpha$ coefficients of each item are greater than 0.8 , and there is good consistency between the various measurement items.

The reliability of the questionnaire is high, which does not mean that the questionnaire has good reliability. Therefore, it is necessary to test the validity of the question, including convergence validity and discriminant validity. Verified, the CR values are not lower than 0.7 and the AVE values are not lower than 0.6, indicating that the model has a good convergence validity. The diagonal value is the square root of AVE, and the off-diagonal value is the square correlation coefficient of each latent variable. Therefore, it also passed the discriminant validity test of the model. In summary, the reliability and validity of the questionnaire passed the test.

\section{Testing of Hypothetical Models and Analysis}

The basis for judging whether the hypothesis is true is the significance level ( $\mathrm{p}$ value) of the path coefficient. It is significant when the p-value is less than 0.05 , the hypothesis is true, otherwise it is not true. Based on the above criteria, the analysis of the results of each hypothesis is shown in Table 3.

Through the analysis of the model, this article basically confirms the influence mechanism of $4 \mathrm{C}+2 \mathrm{~S}$ on $\mathrm{CPV}$ under the clothing scene marketing. The following is a hypothesis test and discussion. 
Table 2. Survey design.

\begin{tabular}{|c|c|c|}
\hline & Dimension & Question item \\
\hline \multirow[t]{22}{*}{$4 \mathrm{C}+2 \mathrm{~S}$} & \multirow[t]{3}{*}{ Customer value } & a1. Good quality \\
\hline & & a2. New style \\
\hline & & a3. Comfortable to wear \\
\hline & \multirow[t]{3}{*}{ Cost } & b1. Reasonable price \\
\hline & & b2. Discounts and offers \\
\hline & & b3. can be reached quickly \\
\hline & \multirow[t]{5}{*}{ Convenient } & $\begin{array}{l}\text { c1. Quickly obtain clothing information by scanning } \\
\text { barcodes, etc. }\end{array}$ \\
\hline & & c2. Selection convenience \\
\hline & & c3. Can quickly place orders \\
\hline & & c4. Payment security \\
\hline & & c5. Rapid logistics \\
\hline & \multirow[t]{4}{*}{ Communication } & d1. Quick online after-sales processing \\
\hline & & d2. Can feedback online \\
\hline & & d3. The salesperson has a good attitude \\
\hline & & d4. The merchant gives a commitment \\
\hline & \multirow[t]{3}{*}{ Surroundings } & e1. Exquisite store decoration \\
\hline & & e2. Clothing display is better \\
\hline & & e3. Cosy atmosphere \\
\hline & \multirow[t]{4}{*}{ Streaming Data } & $\begin{array}{l}\text { f1. You can check the clothing inventory and price dynamics } \\
\text { at any time }\end{array}$ \\
\hline & & f2. There are private customized push \\
\hline & & f3. You can know the latest activities of the store \\
\hline & & f4. Get the latest clothing information and recommendations \\
\hline \multirow{16}{*}{$\begin{array}{l}\text { Customer } \\
\text { Perceived } \\
\text { Value }\end{array}$} & \multirow[t]{3}{*}{ Perceived Function Value } & g1. The clothes I bought are very cost-effective \\
\hline & & g2. The clothes I bought are beautiful \\
\hline & & g3. The clothes I bought are comfortable to wear \\
\hline & \multirow[t]{4}{*}{ Perceived Service Value } & h1. Enjoy the experience \\
\hline & & h2. Provide professional dressing suggestions \\
\hline & & h3. Be respected when buying \\
\hline & & h4. Quick after-sales service \\
\hline & \multirow[t]{4}{*}{ Perceived Social Value } & i1. This dress feels decent \\
\hline & & i2. Having it can improve the way others see me \\
\hline & & i3. Having it can make a good impression on others \\
\hline & & i4. Having it can bring me social recognition \\
\hline & \multirow[t]{5}{*}{ Perceived Emotion Value } & j1. I like the brand concept of the store \\
\hline & & j2. I like this costume experience \\
\hline & & j3. This process makes me feel relaxed \\
\hline & & j4. I feel good when I buy clothes \\
\hline & & j5. This dress will bring me happiness \\
\hline
\end{tabular}


Table 3. Hypothesis model test results.

\begin{tabular}{|c|c|c|c|}
\hline Hypothetical & $\begin{array}{l}\text { Normalized } \\
\text { path factor }\end{array}$ & $P$ value & $\begin{array}{l}\text { Validation } \\
\text { results }\end{array}$ \\
\hline H1a: Customer value is positively correlated with perceived function value & 0.35 & $* * *$ & accept \\
\hline H1b: Customer value is positively correlated with perceived service value & 0.15 & 0.005 & accept \\
\hline H1c: Customer value is positively correlated with perceived social value & 0.22 & 0.016 & accept \\
\hline H1d: Customer value is positively correlated with perceived emotion value & 0.17 & $* * *$ & accept \\
\hline H2a: Cost is positively correlated with perceived function value & 0.63 & $* * *$ & accept \\
\hline $\mathrm{H} 2 \mathrm{~b}$ : Cost is negatively correlated with perceived service value & -0.06 & 0.445 & not \\
\hline $\mathrm{H} 2 \mathrm{c}$ : Cost is positively correlated with perceived social value & 0.08 & 0.503 & not \\
\hline $\mathrm{H} 2 \mathrm{~d}$ : Cost is negatively correlated with perceived emotion value & -0.15 & 0.006 & accept \\
\hline H3a: Convenience is positively correlated with perceived function value & 0.04 & 0.685 & not accept \\
\hline $\mathrm{H} 2 \mathrm{~b}$ : Convenience is positively correlated with perceived service value & 0.31 & $* * *$ & accept \\
\hline $\mathrm{H} 3 \mathrm{c}$ : Convenience is positively related to perceived social value & 0.29 & 0.042 & accept \\
\hline H3d: Convenience is positively related to perceived emotion value & 0.14 & 0.029 & accept \\
\hline H4a: Communication is positively correlated with perceived function value & 0.15 & 0.043 & accept \\
\hline H4b: Communication is positively correlated with perceived service value & 0.23 & 0.001 & accept \\
\hline H4C: Communication is positively correlated with perceived social value & 0.35 & 0.004 & accept \\
\hline H4d: Communication is positively correlated with perceived emotion value & 0.52 & $* * *$ & accept \\
\hline H5a: Surroundings is positively correlated with perceived function value & -0.02 & 0.818 & not accept \\
\hline H5b: Surroundings is positively correlated with perceived service value & 0.31 & $* * *$ & accept \\
\hline $\mathrm{H} 5 \mathrm{c}$ : Surroundings is positively correlated with perceived social value & 0.06 & 0.582 & not accept \\
\hline H5d: Environment is positively correlated with perceived emotion value & 0.20 & $* * *$ & accept \\
\hline H6a: Streaming data is positively correlated with perceived function value & 0.16 & 0.030 & accept \\
\hline H6b: Streaming data is positively correlated with perceived service value & 0.18 & 0.012 & accept \\
\hline H6c: Streaming data is positively correlated with perceived social value & 0.20 & 0.005 & accept \\
\hline H6d: Streaming data is positively correlated with perceived emotion value & 0.23 & $* * *$ & accept \\
\hline
\end{tabular}

1) Customer value has a positive impact on the four dimensions of CPV. Generally, when purchasing clothing, customers must first consider their basic requirements for clothing, that is, quality, style, size, etc. to meet the demand for product value. When all these are satisfied, it will directly affect the customer's perceived function value, that is, the perception of clothing cost performance and comfort. At the same time, the quality of the product value will also affect other psychological feelings of the customer; Since the model is based on scene marketing, the quality of the product will be easily related to the service value perceived by the customer, such as choosing a suitable clothing through in store service will significantly increase the perceived service value of customers. In addition, choosing good quality clothing will increase your customers' perceived social value, such as leaving a good impression on others, changing other 
people's perceptions of themselves and so on; After all these are satisfied, it is easy for customers to feel good about the overall brand or purchase method, and even form emotional dependence, thereby increasing the perceived emotional value of customers.

2) Cost has a positive impact on perceived function value, and the path coefficient is 0.63 , which has a large impact, has a negative impact on perceived emotion value, and has no significant impact on perceived service value and perceived social value. Generally, the higher the cost of consumer spending, the better the quality and style of the clothing purchased, and often increase its perceived function value. Under the same circumstances, the less the customer pays, the easier it is to increase the favorability and satisfaction of customers, that is, increasing the perceived emotion value of customers. However, the cost has no significant effect on perceived service value and perceived social value. It may be because customers mostly send their costs to the function value of the product, and the requirements for service value and social value are relatively low.

3) Convenience has a positive impact on perceived service value, perceived social value, and perceived emotion value, but has no significant effect on perceived function value. Generally, in the Internet era, transaction costs are gradually reduced. Convenience is the basic demand of almost every customer. Under the same conditions, the more convenient the customer's transaction is, the more favorable the customer will be to the service and the more respected and valued the customer will feel, and this sense of respect will often increase the perceived social value of customers, and ultimately affect the perceived emotion value of customers. The reason why convenience is not significant to perceived function value may be that convenience is a service in a broad sense and has little to do with product functions.

4) Communication has a positive impact on all four dimensions. And the path coefficient of the effect on the perceived emotion value reached 0.52 , which has a greater impact. Generally speaking, one of the main differences between online and offline shopping is in communication and service. The effect of offline communication is much higher than that of online communication, and the expression, tone and action of communication between people convey more abundant information, it is easier to increase person's perceived emotion value.

5) Surroundings have a positive impact on perceived service value and perceived emotion value, but have no significant effect on perceived function value and perceived social value. Generally, it is easy for customers to associate environment with service. The better the environment, the easier it is for customers to feel valued, and then affect the perceived emotion value. However, the reason that the environment has no significant effect on perceived function value and perceived social value may be that the environment is an additional value independent of the product, and the perceived function value and the perceived social value are based on the product, and the two are not closely related.

6) Streaming data has a significant impact on the four dimensions of CPV. Generally, in the current Internet era, transaction costs are gradually being re- 
duced, and information transparency is becoming more and more important. Customers can choose clothing with better cost performance by observing real-time price dynamics, network-wide price comparisons, and subscribing to private pushes. So as to improve the perceived function value; And the service of this data will increase the perceived service value; Customers will often increase the perceived social value after choosing clothing that suits them; And these combined effects will increase the perceived emotion value of customers.

The abstract is summarized in Table 4. Based on the above analysis, it can be found that $4 \mathrm{C}+2 \mathrm{~S}$ as a whole can indeed affect various dimensions of $\mathrm{CPV}$ through multiple aspects, and this effect is positive except cost.

\section{Conclusions}

Based on the theoretical analysis of $4 \mathrm{C}$ and $\mathrm{CPV}$, this article through empirical analysis, draws the following conclusions: under the clothing scene marketing model, the value of the customer's perceived function is mainly affected by customer value, cost, communication and mobile data; Customer perception of service value is mainly affected by customer value, convenience, communication, surroundings and streaming data; Customer perception of social value is mainly affected by customer value, convenience, communication and streaming data; Customer perception emotional value is affected by the six factors of customer value, cost, convenience, communication, surroundings and streaming data.

By comparison, it can be seen that customer value, communication and streaming data can all affect these four dimensions. Therefore, regardless of where companies want to improve CPV, they must pay attention to these three factors. For each enterprise, the value of the product is fundamental. Only when the quality of the product passes, it can retain old customers or form word-of-mouth marketing, so that the company has its own loyal fans, thereby forming core competitiveness, especially in the clothing industry. Communication is a bridge for emotional communication between enterprises and customers, and clothes make the man. The clothing industry must pay more attention to brand building

Table 4. Conclusion.

\begin{tabular}{cl}
\hline Serial number & Conclusion \\
\hline 1 & Customer value has a positive impact on the four dimensions of CPV. \\
2 & $\begin{array}{l}\text { Convenience has a positive impact on perceived service value, perceived social value, } \\
\text { and perceived emotion value, but has no significant effect on perceived function value. }\end{array}$ \\
3 & $\begin{array}{l}\text { Convenience has a positive impact on perceived service value, perceived social value, } \\
\text { and perceived emotion value, but has no significant effect on perceived function value. }\end{array}$ \\
4 & $\begin{array}{l}\text { Communication has a positive impact on all four dimensions. } \\
\text { emotion value, but have no significant effect on perceived function value and } \\
\text { perceived social value. }\end{array}$ \\
& Streaming data has a significant impact on the four dimensions of CPV.
\end{tabular}


and customer communication. Here, Inman has done a good job. Attract a group of young literary girls who like to live comfortably. Scene marketing has given traditional online merchants such a better opportunity to express themselves. Streaming data was born on the basis of the development of the Internet and can serve customers. It also allows companies to understand the market in a timely manner. Without the support of data, it is easy for companies to lose touch with the market.

Therefore, for the clothing industry, to seize the opportunity of scene marketing, they must pay attention to increasing customer value, effectively conveying brand concepts to customers, and forming streaming data through technical means to serve customers and their own companies.

Although this article has reached certain conclusions through empirical research, there are still many limitations. Firstly, because scene marketing is a new thing, this article can theoretically draw less on it. Secondly, affected by personal ability and time, the questionnaire of this article is mainly focused on college students, the income level is generally low, and the representativeness of the research results has decreased; Once again, this article did not add intermediate variables in the research process, making the research incomplete. Finally, this article only selected the category of clothing in scene marketing, and selected the "offline experience, online order" mode; the selected angle is narrower. Scholars can choose other models or other categories in future research, or apply the conclusions of this article to other models or categories to verify the model's suitability and improve the model.

\section{Conflicts of Interest}

The author declares no conflicts of interest regarding the publication of this paper.

\section{References}

[1] Cheng, Y.-H. and Tseng, W.-C. (2016) Exploring the Effects of Perceived Values, Free Bus Transfer, and Penalties on Intermodal Metro-Bus Transfer Users' Intention. Transport Policy, 47, 127-138. https://doi.org/10.1016/j.tranpol.2016.01.001

[2] Yang, H., Yu, J., Zo, H. and Choi, M. (2016) User Acceptance of Wearable Devices: An Extended Perspective of Perceived Value. Telematics and Informatics, 33, 256-269. https://doi.org/10.1016/j.tele.2015.08.007

[3] Deng, F. (2015) Research on the Composition of CPV under the Mode of Online Shopping. Commercial Economics Research, No. 30, 66-67.

[4] Lu, Y.X. (2016) The Influence of Clothing Store Image on CPV and Purchase Intention. Woolen Textile Technology, No. 10, 74-79.

[5] Huang, J. and He, T.H. (2016) Research on CPV Influencing Factors of Female College Students' Clothing. Silk, No. 5, 33-38.

[6] Li, J.K. (2020) Research on the Development of Hema Xiansheng under the Background of New Retail. Modern Marketing (Late Issue), No. 1, 160-161.

[7] Wang, J. (2020) Research on Brand Marketing Strategy Based on New Media. 
Productivity Research, No. 1, 120-124.

[8] Guo, Z.H. (2020) Research on the Marketing Strategy of Internet Food Brands Based on 4C Marketing Theory-Taking “Three Squirrels" as an Example. Modern Commercial Industry, 41, 56-57.

[9] Jiang, X.H. (2019) Research on Community Marketing of Virtual Brand Based on “4C” Theory. Shanxi Agricultural Economics, No. 16, 120-121.

[10] Guo, B.D. (2019) Discussion on the Innovation of Network Marketing Mode in the E-Commerce Environment. Modernization of Shopping Malls, No. 12, 37-38.

[11] Baker, J. and Parasuraman, A. (2002) The Influence of Multiple Store Environment Cues on Perceived Merchandise Value and Patronage Intentions. Journal of Marketing, 66, 120-141. https://doi.org/10.1509/jmkg.66.2.120.18470

[12] Jin, Y.F. and Dong, D.H. (2004) An Empirical Study of Factors Affecting Consumer Trust: A Process-Based View. Management World, No. 7, 93-99 + 156.

[13] Wang, X.H. (2008) Research on the Mechanism of Retail Store Environment on Consumer Patronage Behavior. Journal of Beijing Technology and Business University: Social Science Edition, No. 1, 56-63.

[14] Yu, L. and Sun, M.G. (2014) Research on the Relationship between Shopping Environment, CPV and Competitive Advantage of Enterprises. Forum on Statistics and Information, No. 4, 106-112. 